\title{
EL MEDIODÍA Y EL DEMONIO MERIDIANO EN ESPAÑA
}

En uno de sus poemas menores, Juan de Mena describe una visión que tuvo cierto día mientras descansaba de las fatigas de la caza:
Afligido con grand siesta, secutando los venados, entré por vna floresta de frescos y verdes prados; dos corseres arrendados çerca de vna fluente estaban, de los quales non distaban los paies muy arreados...

El poeta pregunta a los pajes a dónde se dirigen, y ellos responden que forman parte de una procesión de "leales amadores", guiada por Cupido y Venus, "Dios et Deessa de amores". No tardan en aparecer los dos dioses, seguidos de una hueste de ilustres figuras tradicionales, unidas en fraternal confusión medieval: Pompeo y Cipión, Paris, Héctor, Archiles, Salomón, Séneca, Dante, Aristóteles, Platón, Virgilio y Horacio, y, cerrando la marcha, el "strólogo Atalante"1.

No son raras en la poesía medieval las procesiones y visiones, eje estructural de muchas obras; pero una procesión que a la vez es visión nos hace pensar en ciertos temas folklóricos, como la Maisnie Hellequin, o la fantástica wilde Jagd de la mitología germánica, o bien la "hueste antigua" española. De hecho, un examen más atento del poema de Mena nos mostrará que, aunque la "hueste" pase por lo común a media noche, no andamos del todo descaminados en nuestra comparación, pues la visión del poeta tiene lugar en hora igualmente "mágica", es decir, a mediodía:

Seguiendo el plaziente estilo

de la deessa Dyana,

posada çerca de vn filo

la hora merediana,

${ }^{1}$ Sobre este personaje virgiliano, cf. M. R. LidA DE MALkiEL, Juan de Mena, poeta del Prerrenacimiento español, El Colegio de México, 1950, pág. 133, nota 6. 
vi lo que persona humana

tengo que iamás non vió ..."

Las creencias populares antiguas, medievales y aun modernas, desde Grecia y Roma hasta Portugal, Bretaña y Escocia, Suecia y Rusia, la India, el Japón y Egipto, han mantenido viva la leyenda de una aparición del mediodía, que unas veces es Pan (o un fauno, sátiro, ninfa o nereida), otras Diana (Hécate o Ártemis), Plutón, Prosérpina o Herodías, el demonio Empusa o bien el guiador -o guiadora- de la wilde Jagd ${ }^{3}$. En la Galia parece haber sido casi siempre Diana ${ }^{4}$, mientras que en España se conocía a Venus como la "strella que aparece a mediodía"s. A manera de ejemplo podemos mencionar a Walter Map, quien en el siglo xir contaba cómo Gerberto (el papa Silvestre II) fué engañado por un fantasma: en una floresta -como Mena-, y también a la hora del mediodía, Gerberto creyó ver una mujer de milagrosa belleza. En el cuento de Henno cum dentibus (Henno with the Teeth, el homem das sete dentaduras del folklore portugués), el héroe ve al mediodía a una encantadora doncella, en medio de una floresta; en otro relato, el salvaje séquito de "Herla" pasa a la misma hora ${ }^{6}$.

Avancemos hasta la segunda mitad del siglo xvir. El Cecrope de Gracián está describiendo a Andrenio varios "plausibles personajes", entre ellos un soldado cobarde: "... aquel soldado nunca falta en las campañas, habla de Flandes, hallóse en el sitio de Ostende, conoció al Duque de Alba, acude a la tienda del general, el demonio del medio día, mantiene la conversación, cobra el primero, y el día de la pelea se haze invisible". Esta figura, que al parecer no es sino un tipo tradicional de soldado, a la manera del "churillero" de Cervantes, resulta ser, en realidad, una como reencarnación de la diosa que encabeza la procesión de amadores en el poema de Juan de Mena. En efecto, ambos son espíritus, ambos son demonios del mediodía, y los caracteriza a ambos la desconcertante peculiaridad de aparecer y desaparecer repentinamente ${ }^{\tau}$.

${ }^{2}$ Cancionero castellano del siglo $x y$, ed. R. Foulché-Delbosc, tomo I (NBAE, vol. XIX), pág. $217 b$.

3 Véanse especialmente el artículo de DrexLer en el Lexikon der griechischen und römischen Mythologie de Roscher, Leipzig, 1894-1897, vol. II, 2a parte, págs. 2832 y sigs.; J. Grimm, Deutsche Mythologie, $4^{3}$ ed., Berlin, 1876, vol. II, pág. 972, y K. Mrisen, Die Sagen vom wütenden Heer und wilden Jäger, München, 1935, pág. 24. No he logrado ver el libro de L. KorTH, Mittagsgespenster, Köln, 1915 .

4 Grimm, loc. cit., y Du Cange, Glossarium, s. v.

5 A. Castro, Glosarios latino-españoles de la Edad Media, Madrid, 1936, pág. 117.

- Walter Map, De nugis curialium, trad. F. Tupper y M. B. Ogle, London, 1924, págs. 218,221 y 223.

${ }^{7}$ Gracián, El Criticón, ed. M. Romera-Navarro, Philadelphia, 1938-194o, vol. 
En otro pasaje del Criticón, Critilo escucha un relato acerca de ciertas personas que

se hazían invisibles a ratos, el día que más eran menester en el trabajo, en la enfermedad, en la prisión, en la hora de hazer la fiança. Olían los males de cien leguas y huían de ellos otras tantas; pero, passada la borrasca, se aparecían como Santelmos. A la hora del comer se hazían muy visibles, y más si olían el capón de leche o de Caspe, en la huelga, en el merendón, al dar barato, que no avía librarse dellos; al punto se los hallava un hombre al lado y en todas partes.

Y al oír esto, Critilo observa: "Sin duda ... que éstos son demonios meridianos, pues todo el día andan assombrados y a la hora del comer se nos comen por pies. Quando más son menester se ocultan, y quando menos se aparecen"s. Así, como éste, era el soldado que acudía a la tienda del general, y así era también el personaje en que pensaba Quevedo cuando definía el "demonio meridiano" como "el amigo doméstico"s.

Esa figura tiene en común con el demonio del mediodía no sólo las repentinas apariciones y desapariciones, sino otro curioso rasgo mencionado por el Cecrope, igualmente auténtico, aunque mucho menos obvio: "mantiene la conversación". El lector podrá admirarse de que a este soldado entrometido, que obliga al general a aguantar su desfachatez, se le dé por añadidura la oportunidad de mantener la conversación. Pues bien, según una leyenda popular, viva todavía en territorio vendo (Lausitz), la "mujer del mediodía", la Pripolniza, alta, vestida de blanco y con una hoz en la mano, recorre los campos en la época de siega, haciendo preguntas a quienes han tenido la imprudencia de no volver a su casa al mediodía. No contestar equi-

II, pág. 189. El editor considera "el demonio del mediodía" como aposición de "general", que en este caso vendría a ser el Duque de Alba, si es cierto que el Duque "compartió con Felipe II el calificativo de el demonio del mediodia, que les dió a entrambos el odio de sus enemigos flamencos". Confieso que no tenía idea de esto, y el editor no precisa en qué lugar de la voluminosa obra de A. J. NAMÈche (Le règne de Philippe II et la lutte religieuse dans les Pays-Bas au xvi ${ }^{\dot{B}}$ siècle, 8 vols., Louvain, 1887) se encuentra ese dato. Pero, aun en caso de que sea exacto, no afectaría al verdadero sentido del pasaje, porque aquí -incluso desde el punto de vista sintáctico- es el soldado, y no el Duque, quien aparece como "demonio del mediodía". No hay duda acerca de la aplicación de semejante epíteto a Felipe II: cf. J. García Mercadal, España vista por los extranjeros, Madrid, s. f., vol. II, pág. 228; Voltaire, Essai sur les mours, en Oeuvres, ed. Moland, Paris, $1877^{-1883}$, vol. XII, págs, 474 y sigs.; Unamuno, Ensayos, Madrid, 1916-1918, vol. IV, pág. 74. Por lo demás, los católicos flamencos aplicaron metafóricamente el término, más tarde, al libre pensamiento francés.

${ }^{8}$ El Criticón, ed. cit., vol. III, págs. 173-174.

- Sentencias, en Obras completas, Prosa, ed. Astrana Marín, Madrid, 1945, págs. $95^{1-95^{2}}$. 
vale a morir: hay que mantener la conversación. Al sonar las dos, la mujer desaparece, y con ella el peligro ${ }^{10}$. Es muy probable que esta blanca mujer del mediodía sea el sol de la época de siega, y el hablar sin interrupción un modo de expresar el delirio causado por la insolación. Pero al mismo tiempo la leyenda puede estar en relación con la charlatanería del soldado de Gracián.

Si avanzamos otros dos siglos, nos encontraremos con Rosalía de Castro y su magnífica interpretación de la secular conciencia del terror del mediodía:

Bien pudiera llamarse, en el estío, la hora del mediodía

noche, en que al hombre, de luchar cansado, más que nunca le irritan

de la materia la imponente fuerza

y del alma las ansias infinitas.

Para ella, es ésta una hora trágica:

Imponente silencio agobia la campiña;

sólo el zumbido del insecto se oye

en las extensas y húmedas umbrías; monótono y constante

como el sordo estertor de la agonía ...11

¿Simple expresión de una reacción personal? No. Lo que tenemos aquí es una versión poética de antiguos temores colectivos, sin duda vivos aún en esa Galicia tan rica en leyendas. En Galicia, como en Portugal, el mediodía, lo mismo que la media noche, sigue siendo una hora mágica. Cuando suenan las doce campanadas, la gente recita versos de conjuro, y se dice que los malos deseos concebidos en ese instante son doblemente eficaces ${ }^{12}$.

Desde el siglo Xvi, los escritores peninsulares se han interesado por el demonio meridiano. Díaz Tanco de Fregenal, ese curioso extremeño, escribió (o pensó escribir, o creyó escribir) un tratado intitulado La porta [léase posta] meridiana, que trata de las cosas admirables acontescidas a medio dia antigua y modernamente ${ }^{13}$. Más aún, en

${ }^{10}$ K. Haberland, "Die Mittagsstunde als Geisterstunde", en Zeitschrift für Völkerpsychologie und Sprachwissenschaft, XIII, 1882, pág. 318; L. LAIsTner, Das Rätsel der Sphinx, Berlin, 1889 , vol. I, págs. 1 y sigs.

${ }^{11}$ En las orillas del Sar (1884), en Obras completas, Madrid, 1952, pág. 586. La puntuación es nuestra.

${ }^{2}$ Cf. João de Vasconcellos, $R L u$, XXV, 1923, pág. 31, y Maria Peregrina DE Sousa, ibid., VI, 1900-, pág. 145. Véase también TH. Braga, $O$ povo portuguez, Lisboa, 1885 , vol. II, págs. 148 y sigs., que cita la oración: "Nem de noite, nem de dia / nem ao pino do meio dia..."

${ }^{18}$ Prefacio de su obra Jardin del alma christiana, Valladolid, 1552, apud GALlardo, Ensayo, vol. II, col. 788 . 
Toledo, el maestro Alejo Venegas refería que en el año de 1543 el demonio mismo se había aparecido en Granada. Como buen pedagogo, Venegas no sólo lo concibe como espíritu malo que induce a los hombres a la desesperación, sobre todo a los curiosos de saber "novedades"14, sino más particularmente como ejemplar escarmiento de los mancebos desobedientes. Citando el Salmo XC de la Vulgata (sobre el cual volveremos en seguida), a negocio perambulante in tenebris; ab incursu et damonio meridiano, comenta:

No te trabucarán los desabrimientos, y, finalmente, no tendrá que ver contigo el demonio meridiano, que es el demonio que clara y abiertamente aparece, para traer a desesperación aquel a quien aparece, que es el hombre que ve él muy curioso de saber y ver novedades y de saber la que los diabológicos dicen ventura que por ellos ha de venir.

También se aparece a los muy rebeldes y desobedientes a sus padres, como apareció este año mil quinientos cuarenta y tres en Granada a un cierto mancebo que dicen que fué muy desobediente a su padre, y siguiólo tanto que le hizo que renegase del baptismo y se diese por su esclavo y lo firmase de su nombre ${ }^{15}$.

Con Lope de Rueda, nuestro demonio se convierte en invectiva contra el intruso y el latoso: “'don diablo meridiano!"16 En 1593, el temible Martín del Río, catedrático de Sagrada Escritura en Salamanca, dedica más de cinco columnas de sus Disquisitionum magicarum libri sex a una discusión confusa y sumamente ingenua sobre qué sea el demonio del Salmo XC ${ }^{17}$. En 1606 , el gramático portugués Duarte Nunes de Leão se sirve del concepto demonio meridiano, evidentemente conocido de todos sus lectores, como ejemplo gracioso de mala etimología de un nombre romance de lugar; habla de un hombre que sostenía que Mérida (Emerita Augusta) no era fundación romana, puesto que "muitos contos de annos antes dos Emperadores Romanos era ja cidade, porque David no Psalmo que começa Que habitat in adiutorio altissimi, fazia menção do diabro Meridiano"18. Mientras tanto, Rodrigo Caro, ilustre precursor de los folkloristas, escribe en Sevilla sus Diaz geniales o lúdricos, y con toda seriedad afirma: "No carece de misterio decir que esta bestia o fantasma se

${ }^{14}$ Cf. A. Castro, "La novedad y las nuevas", $H R$, XX, 1952, págs. 149 y sigs.

${ }^{15}$ Agonia del tránsito de la muerte, en NBAE, vol. XVI, págs. 281 a. Evidentemente, este pasaje fuć añadido después de la primera edición (1537). El texto de la reimpresión moderna sigue la edición de 1565. Hubo otra de Alcalá, 1574 .

${ }_{16}$ Obras, ed. E. Cotarelo, Madrid, 19o8, vol. I, pág. 274.

${ }_{17}$ La primera de las muchas ediciones de esta extensa uanarum superstitionum confutatio, libro de consulta de los inquisidores, se publicó en Madrid, en 1593 . He manejado la edición de Colonia, 1657, págs. 329-332 (lib. II, quaest. xxvi, sect. II, 8).

18 Origem da lingua portuguesa, ed. J. P. Machado, Lisboa, 1945, págs. 327. 
aparece al medio día a los desdichados, porque esto tiene más de verdad ya que de conseja". En oposición con Martín del Río(loc. cit.), Caro cree que el demonio meridiano puede identificarse con el monstruo multiforme conocido bajo el nombre de Empusa, o bien con ese espíritu, más indeterminado aún, que los españoles suelen llamar "la Mala cosa"19.

En muchas de estas discusiones se menciona el Salmo XC (numeración de la Vulgata; Salmo XCI en las demás versiones), versículos $5^{-6}$ : Non timebis a timore nocturno, a sagitta uolante in die, a negotio perambulante in tenebris, ab incursu et demonio meridiano. En el

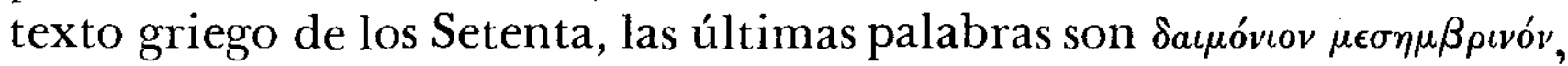

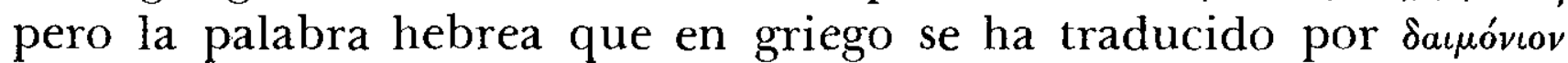
aparece en los diccionarios como 'excidium', 'exitium' o 'turbo exitialis' ${ }^{20}$; de ahí que las traducciones de la Biblia derivadas directa o indirectamente del texto hebreo no digan "demonio meridiano", sino "destrucción del mediodía", idea expresada en diferentes formas. Así, Casiodoro de Reina (1569) habla de la "mortandad que destruya al mediodía" 21 , palabras que, en su revisión de 1602 , Cipriano de Valera convierte en: "mortandad que en medio del día destruya"22. El padre João Ferreira d'Almeida dice: "mortandade que assola ao meio dia" ${ }^{23}$, y algo análogo se lee en la versión brasileña. Giovanni Diodati traduce "sterminio, che distrugge in pien mezzodi"24; Édouard Reuss, "la contagion qui ravage en plein midi" 25; J. F. Ostervald, "la destruction qui fait le dégât en plein midi" 26; Louis Second, "la contagion qui frappe en plein midi" 27 ; la última traducción francesa dice: "le fléau qui dévaste en plein midi" 28 . En la Versión Autorizada inglesa (1611) se lee: "the destruction that wasteth at noone-day"; en la Biblia de Lutero, "Seuche, die im Mittag verderbet"; en el texto holandés de los Estados Generales, "het verderf dat op den middag verwoest"; etc. Pero tanto la primera traducción espa-

${ }^{19}$ Días geniales o lúdricos (1626), ed. de Sevilla, 1884, págs. 302-303. Respecto a la "Mala cosa", cf. mi edición de Torres Naharro, "Propalladia" and other works, Bryn Mawr, 1943-1951, vol. III, págs. 757 y sig. Véase también K. HaberLAND, op. cit., pág. 317 .

${ }^{20}$ Cf. F. Adolpho Collho, "De algumas tradições de Hispanha e Portugal", en $R H i$, VII, 19oo, pág. 419 .

${ }^{21}$ La Sra. María Rosa Lida de Malkiel tuvo la gentileza de consultar esta versión en la biblioteca de la Universidad de California (Berkeley).

${ }^{22}$ Ed. de la Sociedad Bíblica Americana, Nueva York y Londres, 1921.

${ }^{23}$ Apud Coelro, loc. cit. João d'Almeida se convirtió a la fe evangélica en Batavia y publicó su traducción portuguesa del Nuevo Testamento en 1681; el Antiguo Testamento no vió la luz hasta 1748-1753.

${ }^{24}$ Sacra Bibbia, London, s. a.

${ }^{25}$ Le Psautier, Paris, 1875 , pág. 293.

${ }^{26}$ La Sainte Bible, Bruxelles-Paris, 1877.

${ }^{27}$ La Sainte Bible, Paris, 1919.

${ }^{2 s}$ L'Ancien Testament, Société Biblique de Paris, vol. III, 1947. 
ñola de la Vulgata, por Scío de San Miguel $\left(179^{1-1793)^{29}}\right.$, como la posterior de Torres Amat (1823-1825), han mantenido el "demonio meridiano" 30 .

Por supuesto que este demonio individualizado, como observa, por ejemplo, Salomon Reinach, no es sino una invención literaria: "Les interprêtes auteurs du texte grec n'ont pas dû songer à une idée abstraite comme celle de la contagion, mais à une divinité du paganisme. Omnes dii gentium demonia, dit le Psalmiste [Salmo XCV, 5]. Le «démon du [sic] midi» devait aussi être l'un d'eux". O sea, que el demonio cuya huella hemos venido investigando parecería ser "une création de l'exégèse chrétienne à ses débuts, superposée aux données banales de la démonologie populaire" 31 . Sin embargo, el texto latino de la Vulgata, que en España fué el más generalizado y durante largo tiempo el único empleado, daba amplio margen a los seres forjados por la imaginación popular, ya fueran en su origen Diana, Venus o el demonio Empusa, el Espíritu del Trigo u otro cualquiera.

Hasta una imaginación de cultura tan internacional como la de don Juan Valera se inspira en último término en el Salmista, a pesar de que las líneas generales de su visión corresponden más bien a la mitología pagana y cristiana. Cuando, en la famosa excursión al Pozo de la Solana, don Luis, el seminarista de Pepita Jiménez, se encuentra por fin a solas con la inquietante y joven viuda, la naturaleza misma se muestra en su aspecto más sutilmente cargado de augurios, y la atormentada sensibilidad del joven, moldeada por lecturas religiosas, evoca al demonio meridiano. Aquí, en la "sombría espesura" y a la orilla del transparente arroyuelo, estamos de nuevo en el ambiente de aquella "floresta de frescos y verdes prados..., çerca de vna fluente" que describía Juan de Mena:

Mil plantas silvestres y olorosas crecen allí de un modo espontáneo, y por cierto que es difícil imaginar nada más esquivo, agreste y verdaderamente solitario, apacible y silencioso que aquellos lugares. Se concibe allí en el fervor del mediodía, cuando el sol vierte a torrentes la luz desde un cielo sin nubes, en las calorosas y reposadas siestas, el mismo terror misterioso de las

29 Esto a pesar de que se acusó al padre Scío de haberse atenido demasiado al texto hebreo. Sin embargo, puso esta nota al pasaje en cuestión (vol. V, pág. 288): "El Hebréo: Ni de mortandad o exterminio que destruya en el mediodía", y añadió la explicación que San Agustín daba del versículo 6, y hasta la curiosa interpretación de Teodoreto (obispo de Cirro), para quien el "demonio meridiano" era aquel que "después de los banquetes excita los malos designios de los hombres carnales"...

${ }^{30}$ No todas las versiones de la Vulgata lo mantienen; la versión de Douai (1609), por lo menos según sẻ lee en una reedición moderna (The Old Testament, Douay version, en The New Catholic Edition of the Holy Bible, New York, [1948], dice: "the calamity that destroys at noon".

${ }^{31}$ "La religion des Galates", en Revue Celtique, XVI, 1895, págs. 263 y 267. 
horas nocturnas. Se concibe allí la vida de los antiguos patriarcas $\mathrm{y}$ de los primitivos héroes y pastores, y las apariciones y visiones que tenían de ninfas, de deidades y de ángeles, en medio de la claridad meridiana...

Era la primera vez que me veía a solas con aquella mujer y en sitio tan apartado, y cuando yo pensaba en las apariciones meridianas, ya siniestras, ya dulces, y siempre sobrenaturales, de los hombres en las edades remotas.

Más tarde, cuando, al escribir a su tío, recuerda don Luis la portentosa entrevista, dice:

Su meridiana aparición, en lo más intrincado, umbrío y silencioso de la verde enramada, me trajo a la memoria todas las apariciones, buenas o malas, de seres portentosos y de condición superior a la nuestra, que había yo leído en los autores sagrados y en los clásicos profanos. Pepita, pues, se mostraba en los ojos y en el teatro interior de mi fantasía, no como iba a caballo delante de nosotros, sino de un modo ideal y etéreo, en el retiro nemoroso, como a Eneas su madre, como a Calímaco Palas, como al pastor bohemio Kroco la sílfide que luego concibió a Libusa, como al Patriarca los ángeles en el valle de Mambré, como a San Antonio el hipocentauro en la soledad del yermo.

Y luego, mientras vuelve al lugar, caminando tranquilo en su mula, le viene por fin a la cabeza el versículo del Salmo XC, que sin duda se había estado agitando ya en el fondo de su espíritu (y en el del hábil Valera): "Me figuré ... que algún demonio se agitaba en torno mío, sugiriéndome mil disparates" 32 . Así queda revelada finalmente la fundamental realidad de Venus ${ }^{33}$, de Palas $^{34}$, de la sílfide ${ }^{35}$, de los ángeles de Mambré36 y del hipocentauro" ${ }^{37}$ : es el "demonio meridiano", oculto hasta entonces, a los ojos del lector no enterado, por una serie de sugerentes ilustraciones poéticas.

Más cerca de nosotros, y en Francia, Paul Bourget hace entrar al sensacional demonio de la Vulgata en el título de su novela Le démon

32 Pepita Jiménez, ed. Clás. cast., Madrid, 1927, págs. 68-69 y 74 .

${ }^{33}$ Cf. Eneida, I, 405: "Et uera incessu patuit dea..."

${ }^{34}$ Valera alude al himno de Calímaco a Palas (versos 71 y sigs.), en que Tiresias recibe cruel castigo por haber visto un instante a la diosa en el baño.

${ }^{35}$ Krok fué un rey legendario de gran parte de Bohemia, cuya hija Libussa, según es fama, fundó la ciudad de Praga y dió comienzo a una dinastía que gobernó a Bohemia desde el siglo ix hasta el xiv.

${ }^{36}$ Génesis, XVIII, 1: "Apparuit autem [a Abraham] Dominus in conualle Mambre sedenti in ostio tabernaculi sui in ipso feruore diei. Cumque eleuasset oculos, apparuerunt ei tres uiri stantes prope eum ..."

${ }^{37}$ Cf. $P L$, vol. XXIII, col. 22. San Jerónimo cuenta cómo San Antonio vió al hipocentauro, así como faunos y sátiros: "Et iam media dies coquente desuper sole feruebat ... conspicit hominem equo mixtum cui opinio poetarum Hippocentauro uocabulum indidit". 
de midi (1914), si bien su objeto es aplicar metafóricamente la idea de la destrucción del mediodía a la vida de un intelectual ${ }^{38}$. Pero para otros novelistas modernos, el demonio ha sido y sigue siendo el antiguo diablo ctónico. En la cuarta parte de su tetralogía Olav Audunsson (1925-1927), Sigrid Undset nos describe cómo en un prado, a mediodía, Olav ve aparecer de pronto a su difunta mujer:

Lo primero que se le ocurrió fué que la visión fuera un fantasma,... o quizá algo más que eso: a negotio perambulante in tenebris, ab incursu et damonio meridiano. Así, en la oración de la noche pedimos protección contra aquella cosa que vela en la oscuridad, y contra el asalto de los malos espíritus al mediodía. $\mathrm{Y}$ en verdad, ya muchas veces había sentido que, justamente en el silencio del calor meridiano, andan rondando muchas cosas que no podemos ver... ${ }^{39}$

Los europeos -incluso los intelectuales- siguen percibiendo esa cualidad misteriosa y turbadora del mediodía. En el Bocksgesang de Franz Werfel, un médico dice, a propósito del monstruoso hijo de Stevan Milic: "Los antiguos pensaban que de la temblorosa naturaleza, en pleno mediodía, podía surgir una cosa, informe pero visible, horrible y llena de majestad, capaz de agostarlo todo a su paso, como la visión del Todo comprimida en un segundo..."40 Y no hay que olvidar la importancia del mediodía para el surrealismo. Una vez. Salvador Dalí "perdió" por casualidad, frente al Waldorf de Nueva York, una larguísima pieza de pan francés (especialmente preparada para él en los hornos del vapor Champlain); al punto volvió la cabeza, en espera del extraordinario efecto que imaginaba; pero se encontró con que el pan se había esfumado sin dejar rastro y sin que nadie pareciera haberse dado cuenta del extraño suceso. Esto casi se pasaba de surrealista; pero, buen español al fin, Dalí cayó en seguida en la cuenta: "Eran exactamente las doce, la hora de los fantasmas meridianos ..." 41

University of Pennsylvania.

Joseph E. GiLlet

ss "Pour eux [para nuestros antepasados] le demonium meridianum était un véritable Démon, la tentation du milieu du jour, particulière aux cloîtres. Ils avaient observé que la sixième heure, notre midi, est redoutable aux Religieux. La fatigue du corps, épuisé par la veille et le jeûne, gagne l'âme qu'un trouble envahit ... Je donne, moi, le même nom à une autre tentation ... C'est celle qui assiège l'homme, au midi, non pas d'un jour, mais de ses jours, dans la plénitude de ses forces. Il a conduit sa destinée, jusque-là, de vertus en vertus, de réussite en réussite. Voici que l'esprit de destruction s'empare de lui, -entendez-bien: de sa propre destruction". Le démon de midi, Paris, 1914, págs. 8-9.

${ }^{39}$ Según la trad. inglesa de A. G. Chater (The Master of Hestviken, IV, The son avenger), New York-London, 1930, pág. 115.

${ }^{40}$ The Theatre Guild Anthology, New York, 1915 (acto I, escena XII).

${ }^{41}$ The secret life of Dali, New York, 1942, pág. 336. 